\title{
Translational Molecular Imaging of Diabetes
}

\author{
Ping Wang • Anna Moore
}

Published online: 29 June 2013

(c) Springer Science+Business Media New York 2013

\begin{abstract}
Diabetes mellitus contributes to significant morbidity and mortality worldwide. Translational medicine and research facilitate the transition of in vitro and experimental animal research to human applications. Molecular imaging is one of the powerful tools for translational research in diabetes, which accelerates transition of laboratory hypotheses into the clinic. These imaging tools are also instrumental for furthering our understanding about the causes that trigger diabetes and facilitate its progression. Imaging of therapeutic response is yet another avenue that can be explored in our attempt to find a cure for this disease. In this review we briefly summarize molecular imaging studies that show promise for clinical translation. Emphasis is placed on imaging of endogenous and transplanted beta cell mass, including application of various imaging modalities and approaches. Finally, the review attempts to define the future role of these non-invasive imaging techniques in diabetes research and clinical care.
\end{abstract}

Keywords Diabetes $\cdot$ Translational medicine $\cdot$ Molecular imaging $\cdot$ Islet transplantation

\section{Introduction}

Diabetes mellitus is hallmarked by high levels of blood glucose caused by lack of insulin production, insulin resistance in peripheral tissues, or both [1] and represents a

\footnotetext{
P. Wang $\cdot$ A. Moore $(\bowtie)$

Molecular Imaging Laboratory, MGH/MIT/HMS Athinoula A. Martinos Center for Biomedical Imaging, Massachusetts General Hospital/Harvard Medical School, Building 75, 13th Street, Charlestown, MA 02129, USA

e-mail: amoore@helix.mgh.harvard.edu
}

worldwide health problem. Studies show that approximately 280 million people or $6.4 \%$ of the world population suffer from this disease. These numbers could increase to 438 million by 2030 [2, 3] causing diabetes-related healthcare costs to rise up to $40 \%$ of the total healthcare budget in high incidence countries. In addition, diabetes increases a risk for cardiovascular disease, and is the leading cause of kidney failure, lower limb amputations, and adult onset blindness.

"Translational medicine" is a research that aimed at fast-tracking biomedical advances in pre-clinical research for patient benefits $[4,5]$. Molecular imaging, a rapidly emerging biomedical research discipline, has a high potential to provide insights into when, why, and how diabetes occurs, as well as to devise new ways to treat the disease. Imaging is one of the most valuable tools for translational medicine of diabetes since it could provide real time non-invasive data of various biological parameters and their functions as they relate to diabetes progression and treatment.

The major aim of this review is to discuss current stateof-the-art strategies for diabetes imaging. We focus on the present status of the techniques for non-invasive imaging and quantification of endogenous and transplanted beta cell mass (BCM) since this parameter ultimately defines glycemic status of the patient. We concentrate mainly on magnetic resonance imaging (MRI) and nuclear imaging, as these are the two modalities with the highest potential for clinical translation as it relates to diabetes imaging. While optical imaging offers excellent possibilities for imaging beta cells and insulitis in vitro or in animal models, translational potential of this approach is hampered by deep location of the pancreas in the body and by the difficulty of detecting fluorescence with the currently available technology [6]. 


\section{In Vivo Imaging of Endogenous BCM}

The loss of functional beta cells is seminal in the development of both type 1 diabetes (T1D) and type 2 diabetes (T2D). The T1D results from autoimmune destruction of beta cells, while T2D leads to beta cell dysfunction due to insulin resistance [7, 8]. Metabolic testing of pancreatic islet by assaying plasma insulin or C-peptide combined with more or less sophisticated calculations provides information about the degree of insulin resistance or secretory failure. It also provides certain correlations of endocrine function with BCM. However, these indirect measures of beta cell mass/function are not dynamic and have the same limitations as histology studies [9, 10]. Results obtained from autopsy samples of the human pancreas nicely correlate the percentage of beta-cell volume with fasting glucose levels even before the onset of diabetes, supporting the idea that beta-cell mass loss occurs early, and to a measurable extent, during diabetes progression, which points to the possibility for early diagnosis of this disease [11]. Furthermore, with the development of new drugs and modern protocols for islet transplantation, the promise of preservation or even expansion of beta-cell mass has become very attractive. In both cases tools for longitudinal non-invasive assessment of beta-cells mass are critically needed. From a clinical standpoint, the ability to image BCM non-invasively would greatly aim in aiding patient management and in designing individualized antidiabetic therapies [12].

Imaging of BCM is a major challenge due to the small size of pancreatic islets, islet density throughout the pancreas, and lack of inherent contrast from the surrounding tissues. Furthermore, the endogenous pancreatic islets are dispersed throughout the pancreas and constitute only $2-3 \%$ of the pancreatic volume [13-15]. Lack of specific validated markers on beta-cell surface that could be targeted by contrast agents add to the complexity of this endeavor.

\section{MR Imaging of Beta-Cells}

Contrast in MR images originates from local variations in tissue water protons and the chemically bound state of proton concentrations. Currently, there are two approaches that have been developed for monitoring beta-cell function using manganese-enhanced magnetic resonance imaging (MEMRI) and a zinc-responsive T1 agent.

\section{Imaging Islet Function by Manganese-Enhanced MR}

Manganese is a longitudinal relaxation time (T1)-shortening MRI contrast agent that enters the pancreatic beta-cell through voltage-gated calcium channels. It has been demonstrated that in the presence of $\mathrm{MnCl} 2$, glucoseactivated pancreatic islets yield significant signal enhancement in T1-weigheted MR images in vitro and in animal models of diabetes [16-23]. This approach has also been tested in preliminary studies in patients with T2D. After reviewing 243 scans that included 41 examinations run on 24 patients with T2D and 202 examinations run on 119 normoglycemic patients, the authors concluded that MEMRI discriminated T2D from non-diabetic patients, based on the difference of the signal enhancement of the pancreas $[24 \cdot \bullet]$.

While these studies opened the door for MRI visualization of the native islets in humans, there are several outstanding issues that will likely limit future translation of this approach to the clinically accepted routine method. The major shortcoming of MEMRI is cellular toxicity of manganese. Emphasis in the future studies should be given to the experimental methodology aiming at delivering significant, yet safe, amounts of manganese to the target areas of interest [25]. With regard to resolution, the high magnetic field that is presently required for MEMRI limits this approach to research on animal models until safety concerns have been adequately dealt with [21].

Imaging Beta-Cell Exocytosis Using a Zinc-Responsive T1 Agent

Zinc plays a critical role in biosynthesis, transport, maturation through the Golgi apparatus, and secretion of insulin by beta cells. Lubag et al. [26•] explored the possibility of detecting divalent zinc ions co-released with insulin from beta cells in response to high glucose by MRI using the $\mathrm{Zn}$ $(2+)$-responsive T1 agent, GdDOTA-diBPEN. Image contrast was significantly enhanced in the mouse pancreas after the injection of glucose followed by a low dose of the $\mathrm{Zn}$ sensor. The pancreas was not enhanced in mice not subjected to glucose stimulation (Fig. 1) or treated with streptozotocin (STZ) to induce beta-cell apoptosis. Images of mice fed a high-fat diet over a 12-week period showed a larger volume of $\mathrm{Zn}$ contrast-enhanced pancreatic tissue. This MRI sensor offers the exciting potential for evaluation of beta-cell function in vivo [27, 28]. Since the shortening T1 effect of GdDOTA-diBPEN contrast agent used in this study is substantially related to the presence of human serum albumin [29], the in vivo sensitivity of the probe for zinc detection still needs further evaluation.

\section{Nuclear Imaging of BCM}

The use of radiotracers includes two major imaging modalities: positron emission tomography (PET) and single-photon emission computed tomography (SPECT). Nuclear imaging allows for non-invasive measurement of 
A

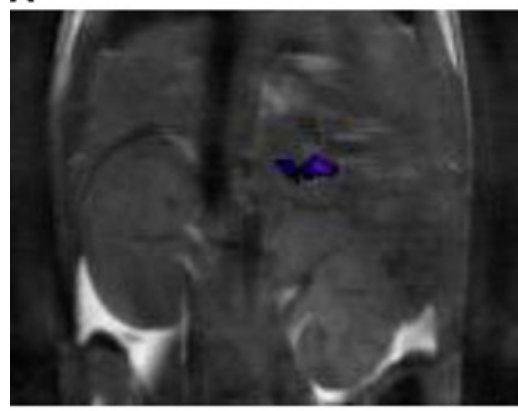

Saline +

GdDOTA-diBPEN

(12-wk old)

Fig. 1 Representative grayscale T1-weighted MR images of a single slice through the abdomen that contains a portion of pancreatic tissue ( $1 \mathrm{~mm}$ slice without fat saturation) of 12-week-old control animals after injection of either saline (a) or glucose (b) followed by GdDOTA-diBPEN. The colored overlays represent a 3D composite of

radioligand uptake and clearance. It is sensitive in the picoto nanomolar range and its results can be deconvoluted into quantitation of ligand or receptor concentration. Several targets have been tested so far for nuclear imaging of BCM including the sulfonylurea receptor (SUR) [30-33], somatostatin receptor type-2 (SSTR2) [34, 35], serotonin receptor [36, 37], glucagon like peptide-1 receptor (GLP1R) [38-41], IC2 antigen [42], dopamine D-2 receptor [43], type 2 vesicular monoamine transporter (VMAT2) [44-49], and presynaptic vesicular acetylcholine transporter [50*]. Among these targets, translational clinical studies have been developed for imaging VMAT2 and the presynaptic vesicular acetylcholine transporter.

Type 2 vesicular monoamine transporter (VMAT2), firstly found in the brain, is also expressed on the surface of beta cells in the pancreas in the form of a monoamine transporting integral membrane protein. Tetrabenazine (TBZ) and Dihydrotetrabenazine (DTBZ) specifically bind to the synaptic VMAT2 [51, 52] and are approved for clinical use. Several groups showed the utility of these agents for targeting VMAT2 for BCM imaging in animal models [44-49]. Encouraged by these promising initial results in animal models, Freeby et al. [53॰] performed the first clinical translational study that showed a reduction in pancreatic uptake of 11C-DTBZ in long-standing T1D patients compared to the uptake in the pancreas of healthy control subjects by PET. Quantification of 11C-DTBZ uptake in the pancreas was identified as an indirect measurements of BCM.

In another clinical study carried out by Goland et al., in 2009 [54], 11C-DTBZ PET was performed on six longstanding T1D patients and nine healthy subjects. The VMAT2 binding potential was estimated by using the renal cortex as reference tissue. The results suggested that $11 \mathrm{C}$ -

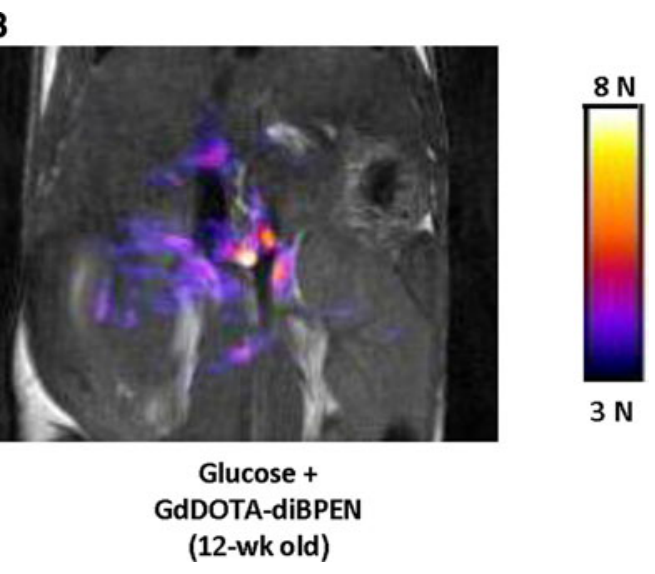

those pixels in each of the 14 slices where the water image intensity increased by threefold or more over the average noise $(\mathrm{N})$ after injection of saline plus agent or glucose plus agent. Reprinted from Proc Natl Acad Sci U S A. 2011, 108:18400-5, National Academy of Sciences publication, with permission (Color figure online)

DTBZ PET allowed for quantification of VMAT2 binding in the human pancreas. However, the functional binding capacity appeared to overestimate BCM given the nearcomplete depletion of BCM in long-standing T1D patients, which might be due to higher non-specific binding in the pancreas than in the renal cortex.

Eriksson et al. [55] tested 18F-fluoroethyl-dihydrotetrabenazine (18F-FE-DTBZ) PET imaging for quantifying BCM in clinically relevant large animal models and humans in 2010. Three pigs were intravenously administered 18F-FE-DTBZ and examined by PET/CT. The uptake of the agent in human pancreatic tissue obtained from the patients with T1D, T2D and healthy controls was assessed in vitro by autoradiography. The results show that $18 \mathrm{~F}-\mathrm{FE}-$ DTBZ bind to VMAT2 with high specificity in pure islet tissue in vitro. However, there was a high non-displaceable binding to exocrine tissue. In addition, in vivo tracer metabolism and dehalogenation result in severe underestimation of porcine pancreatic VMAT2 expression and BCM. The authors concluded that the results did not support the use of $18 \mathrm{~F}-\mathrm{FE}-\mathrm{DTBZ}$ as a suitable tracer for in vivo $\mathrm{BCM}$ imaging.

Lin et al. [56॰] investigated biodistribution and radiation dosimetry of 18F-fluoropropyl-dihydrotetrabenzazine (18FAV-133)(18F-FP-DTBZ) in humans. The whole-body PET scan proved that the radioactivity uptake in the brain was the highest at $10 \mathrm{~min}$ after injection. High-absorbed doses were found in the pancreas, liver, and upper large intestine wall. Among them, the highest uptake was found to occur in the pancreas. The authors concluded that $18 \mathrm{~F}-\mathrm{AV}-133$ was safe and had the appropriate biodistribution and radiation dosimetry for imaging VMAT2 sites in humans. A clinical trial sponsored by Avid Radiopharmaceuticals is currently on the way to test quantitative PET imaging of pancreatic 
BCM in T2D patients with 18F-AV-133 (clinicaltrials.gov Identifier: NCT01710371).

Aimed at increasing the stability against defluorination, which was previously observed for 18F-FE-DTBZ, Jahan et al. [57•] synthesized and tested a novel deuterated radioligand 18F-FE-DTBZ-d4. The in vivo pharmacokinetics and pharmacodynamics of this probe were studied in a porcine model by PET/CT imaging. The authors concluded that $18 \mathrm{~F}-\mathrm{FE}-\mathrm{DTBZ}-\mathrm{d} 4$ was a promising candidate for preclinical and clinical studies for imaging focal clusters of beta cells, such as in intramuscular islet grafts. More recently, Normandin et al. [58••] evaluated 18F-AV-133 for quantitative PET imaging of BCM in healthy control subjects and T1D patients. Standardized uptake values were calculated as the net tracer uptake in the pancreas normalized by injected dose and body weight. The total volume of distribution, the equilibrium ratio of tracer concentration in tissue relative to plasma, was estimated by kinetic modeling with arterial input functions. Binding potential, the steady-state ratio of specific binding to nondisplaceable uptake, was calculated using the renal cortex as a reference tissue devoid of specific VMAT2 binding. The results showed that the mean pancreatic standardized uptake value, total volume of distribution, and binding potential were reduced by 38,20 , and $40 \%$, respectively, in T1D patients compared with healthy control. These studies concluded that quantitative evaluation of islet density and aggregate BCM could be performed clinically with 18F-AV-133 (Fig. 2).

The above-mentioned clinical studies encouragingly concluded that BCM quantification is feasible in T1D patients and in healthy controls, despite an ongoing debate regarding VMAT2 imaging of BCM [59-62]. Further investigations and discussions will definitely continue addressing these and other issues before these radiotracers are utilized for routine noninvasive quantification of BCM in vivo in the native pancreas in clinical setting.

Presynaptic vesicular acetylcholine transporter is yet another target that has been tested in the clinic for BCM imaging. Clark, et al. [50॰] utilized 18F-fluorobenzyltrozamicol (18F-FBT), which binds to presynaptic vesicular acetylcholine transporter, for PET scanning in two adult rhesus monkeys and one human subject. In both monkeys and a human subject, the pancreas was intensely FBT avid, with uptake greater than in any other organ at 30,60, and 90 min. These data suggested that $18 \mathrm{~F}-\mathrm{FBT}$ was feasible for neuroreceptor imaging of the pancreas in animal models and in humans. This method could allow researchers to interrogate functions under the control of the autonomic nervous system in the pancreas, with applications possible for endogenous and transplanted islets. Also, the authors believed that as beta-cell function was intimately related to parasympathetic cholinergic input, FBT activity detected in the pancreas might correlate with the
Fig. 2 Representative 18F-FP(1)-DTBZ PET images. a Image acquired for healthy control subject showed high uptake of tracer in pancreas. b Pancreas uptake was reduced in type 1 diabetes patient. Both images represent PET data summed from 0 to 90 min after injection and are displayed on common scale (0-20 SUV - that is, radioactivity normalized by injected dose and body weight). GI 5 gastrointestinal tract; $\mathrm{K} 5$ kidney; L 5 liver; M 5 myocardium; PB 5 pancreas body; PH 5 pancreas head; PT 5 pancreas tail; S 5 spleen; V 5 vertebrae. Reprinted from J Nucl Med 2012; 53:908-916, an ANMMI publication, with permission

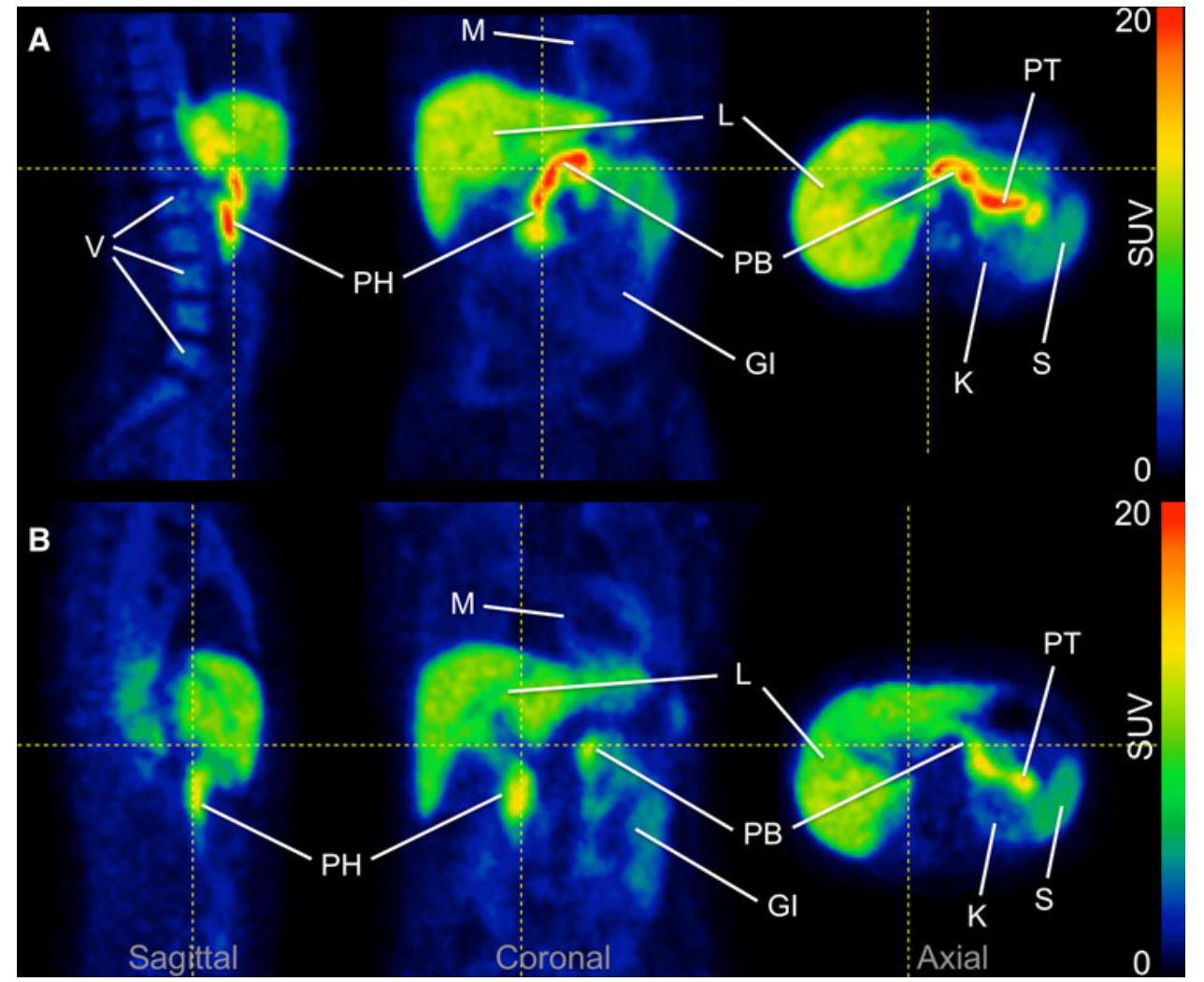


mass of insulin-producing beta-cells. However, a significant uptake of 18F-FBT was also observed in salivary gland, liver, and gallbladder. This study showed considerable promise pending further validation in clinic.

\section{Translational Imaging of Transplanted Islets}

Clinical islet transplantation has progressed over the past 12 years with over 750 patients with T1D receiving islet transplants internationally [63]. However, the promise of allogeneic islet transplantation has been hindered by immunologic damage and death from hypoxia, the requirement for post-transplant immunosuppression, and limited supply of pancreatic islets [64]. Even with improved protocols, long-term survival of the grafts is bleak, with most recipients requiring additional exogenous insulin therapy or a second transplant within a short time to meet their metabolic needs [65]. Developing strategies to image transplanted human islets can solve technical barriers toward using this technology for monitoring clinical islet transplantation [66].

\section{MRI Tracking of Transplanted Islets}

Transplanted islets have been labeled with superparamagnetic iron oxide (SPIO) nanoparticles [67-70] or paramagnetic gadolinium based agents for negative (hypointense) and positive (hyperintense) [71] contrast 1H MRI, respectively. In addition, transplanted islets have been monitored with 19F MRI in animal models [72, 73]. Potential translation of these findings to the clinical settings requires validation of these methodologies in clinically relevant large animal models. The first study in large animals was reported by the group from Johns Hopkins University (Prof. Jeff Bulte's Laboratory) in 2007. Human islets labeled with immunoprotective iron oxide-loaded magnetic capsules were detected with real-time MRI [74•]. In 2009, our group from Massachusetts General Hospital, demonstrated the possibility of longitudinal MRI monitoring of pancreatic islets after transplantation in baboons (Papio hamadryas) [75•]. In this model autologous islet grafts obtained after partial pancreatectomy were transplanted in the liver and under the kidney capsule. The Food and Drug Administration (FDA) approved SPIO preparation Feridex ${ }^{\circledR}$, was used for islet labeling. T2*-weighted MR images generated on a $1.5 \mathrm{~T}$ clinical scanner revealed the renal subcapsular islet graft as a pocket of signal loss disrupting the contour of the kidney at the transplantation site. Islets transplanted in the liver appeared as distinct signal voids dispersed throughout the liver parenchyma (Fig. 3) [75]. This study established a method for the noninvasive, longitudinal detection of pancreatic islets transplanted into non-human primates using a low-field clinical MRI system [14].

The first MR imaging study in humans was performed by the Geneva group in 2008 [76]. Islets labeled with SPIO nanoparticles were transplanted into four patients with T1D. All patients discontinued insulin therapy after transplantation. Three out of four patients had normal liver intensity on pre-transplant images. Iron-loaded islets could be identified after transplantation as hyperintense spots within the liver. The study showed the overall safety of transplanted islets labeled with iron oxide based contrast agent. However, the number of infused islets did not correlate with the number of signal voids on MR imaging raising questions regarding labeling efficiency and image analysis.

Later, Saudek et al. [77•] reported their results of a clinical study that tested the feasibility and safety of MR imaging of transplanted islets in humans. Islets were labeled with the SPIO-based formulation Ferucarbotran ${ }^{\circledR}$ and transplanted into the liver of eight T1D patients through the portal vein. The liver area was examined the next day and 1, 4, and 24 weeks posttransplant using a $3 \mathrm{~T}$ MR scanner. In all recipients, significant C-peptide levels and near-normal $\mathrm{HbA} 1 \mathrm{c}$ values were achieved with 50-80 \% insulin dose reduction. No side effects related to the labeling procedure were documented. A significant islet spot number decrease (on average $60 \%$ ) was detected 1 week post transplantation with a subsequent slight decrease for up to 24 weeks. These data showed that MR detection of Ferucarbotran-labeled islets enabled their long-term noninvasive visualization, which correlated with sustained C-peptide production. While the presented technique shows promise for clinical evaluation of initial islet engraftment and survival, the question regarding correlation between the infused and detected islets remains open.

As new transplantation sites with beneficial vascularization are being investigated, in vivo imaging plays an increasing role in evaluating the outcome of these grafts. Christoffersson et al. [78, 79] evaluated vascularization of islet grafts implanted in striated muscle of mice and humans as an angiogenic site. Intra-islet vascular density and blood flow in these grafts were visualized with intravital and confocal microscopy in mice and by MRI in three autotransplanted pancreatectomized patients. Contrary to the liver-engrafted islets, islets transplanted to mouse muscle were revascularized with vessel densities and blood flow entirely comparable with those of islets within intact pancreas in both mice and humans. The experimental data were confirmed in autotransplanted patients where higher blood perfusion of the grafts compared to adjacent muscle was found using high-resolution MRI. This study showed that the striated muscle could be a promising site for islet transplantation that promotes full revascularization of 

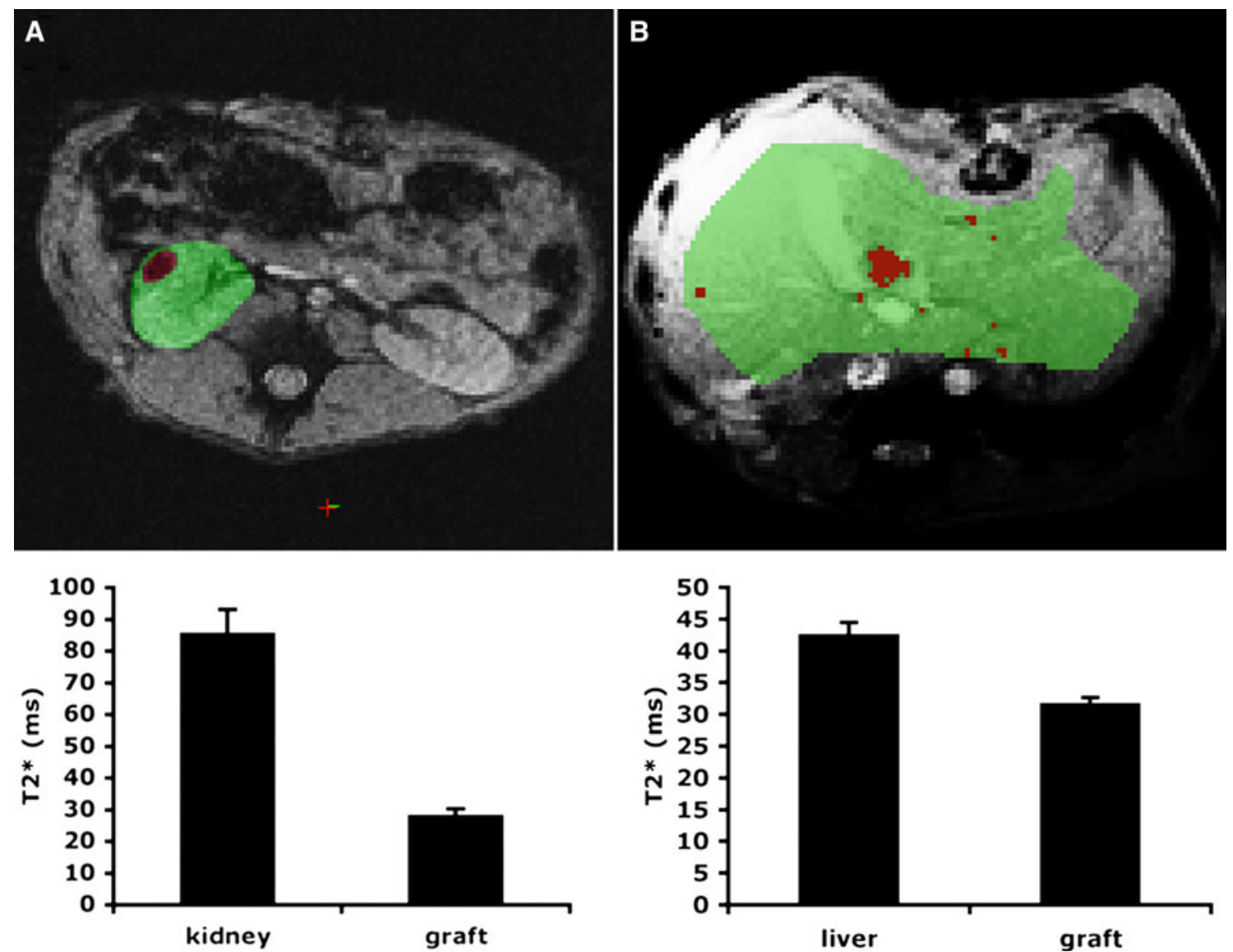

Fig. 3 Magnetic resonance image segmentation for assessment of relative transplanted islet mass in the kidney (a) and liver (b) transplantation models. A region of interest (ROI) was drawn manually around the kidney or liver. An automated algorithm was used to segment the ROI into kidney/liver parenchyma (green) and islet graft (red) based on

implanted grafts. Besides the forearm muscle, several other islet transplantation sites including the gastric submucosal space [80, 81] and adrenal glands [82] have also been investigated. Clearly, non-invasive imaging could greatly assist in evaluating these sites and in monitoring islet survival aiding to clinical translation of these new approaches.

Nuclear Imaging of Transplanted Islets

\section{F-Fludeoxyglucose (18F-FDG) PET Imaging of Transplanted Islets}

Clinically used 18F-FDG as a glucose analog is taken up by high-glucose-using cells forming a trapped 18F-FDG-6phosphate derivative. As a result, the distribution of $18 \mathrm{~F}-$ FDG could be used for correlation with glucose uptake by cells in the body including pancreatic islets. PET-18F-FDG imaging has been tested for detection of transplanted islets in an animal model [83]. Following that, clinical feasibility

$\mathrm{T} 2 *$ values. Representative images (top) and the corresponding $\mathrm{T} 2 *$ values_SD (bottom) are shown. The differential between the two labels was sufficiently large to reliably identify the graft $(P<0.05)$. Reprinted from Transplantation, 2009, 87: 1659-1666, Wolters Kluwer Health publication, with permission (Color figure online)

of detecting transplanted islets labeled with 18F-FDG was demonstrated for the first time in 2007. Eich et al. [84•] labeled porcine islets in vitro with $18 \mathrm{~F}-\mathrm{FDG}$ and infused them intraportally into the liver of anesthetized pigs. PET/ CT scanning showed heterogeneous distribution of the radioactivity in the liver with the peak percentage of infused radioactivity of $54 \pm 5.1 \%$. There was no accumulation in the lungs or brain; extrahepatic radioactivity was evenly distributed in the animal body except for urinary excretion. The authors concluded that almost $50 \%$ of the islets were damaged to the extent that the FDG was released within minutes after intraportal transplantation. The distribution of radioactivity without accumulation in the brain indicated that the activity released from lysed islet cells was in the form of 18F-FDG-6-phosphate rather than native 18F-FDG. In 2009, the same group [85••] reported on the clinical study using islets labeled with $18 \mathrm{~F}$ FDG and transplanted to T1D patients. A fraction of the islets $(23 \%)$ were labeled with 18F-FDG and carefully mixed with unlabeled islets just prior to intraportal 
transplantation. A PET/CT scan was performed for $1 \mathrm{~h}$ during islet transplantation in five patients receiving six transplants. The peak radioactivity concentration in the liver was found at $19 \mathrm{~min}$ after the beginning of islet infusion and corresponded to only $75 \%$ of what was expected, probably indicating that islets were damaged during the transplantation procedure. Distribution of radioactivity in the liver was heterogeneous with wide variations in location and concentration. A peak of C-peptide was found in plasma during and immediately after transplantation in all subjects. The clinical outcome in all patients was comparable to that previously observed indicating that the $18 \mathrm{~F}-\mathrm{FDG}$ labeling procedure did not harm the islets. Beyond this, the short radioactive half-life and retention within the islets limit the use of this method.

\section{GLP-1R SPECT Imaging of Transplanted Islets}

The GLP-1R, which belongs to G protein-coupled receptor family, is highly expressed on the beta cell cellular membrane. Glucagon-like peptide-1 (GLP-1) is a potent antihyperglycemic hormone that induces glucose-dependent insulin secretion. The GLP-1 has a short half-life of less than $2 \mathrm{~min}$ in vivo due to degradation by the dipeptidyl peptidase-IV. GLP-1 analogues, such as exendin-4 and exendin-3, have similar biological activity but a longer in vivo half-life. Several GLP-1 analogue based molecular imaging probes targeting GLP-1R have been used for imaging endogenous beta cell [38-41, 86], insulinoma cell [87-90] and transplanted islets [91, 92] in animal models.

For translational studies, Christ et al. [93] tested ${ }^{111} \mathrm{In}$ labeled GLP-1R agonist ${ }^{111}$ In-DOTA-exendin-4 for localizing insulinomas in six patients using SPECT/CT. After the injection of ${ }^{111}$ In-DOTA-exendin-4 $(90 \mathrm{MBq}, 30 \mu \mathrm{g}$ of peptide), SPECT/CT of the abdomen was performed at $20 \mathrm{~min}, 4 \mathrm{~h}, 23 \mathrm{~h}, 96 \mathrm{~h}$, and up to $168 \mathrm{~h}$ post injection. In all six cases, insulinomas were successfully detected, which permitted a successful surgical removal of the tumors in all patients.

Encouraged by these studies, clinical testing of GLP-1R has been applied for imaging of transplanted islets in patient muscle [94••]. In this clinical translational case report, a 48-year-old woman underwent the resection of the pancreas to remove insulinoma. Healthy islets $(97,000$ islet equivalents) isolated from the surgical specimen after ex vivo tumor resection were transplanted into the left brachioradialis muscle. Islet survival was justified by the limited response to intravenous glucose tolerance test at $48 \mathrm{~h}$ after surgery. One year after transplantation, a whole-body planar scan was performed after intravenous administration of $96 \mathrm{MBq}$ of ${ }^{111}$ In-DTPA-exendin-4. As expected, focal accumulation of the radiolabeled GLP-1 analogue was visible in the left forearm at the site of islet transplantation.
Tracer uptake was visible in the duodenal region, most likely corresponding to the islets in the pancreas remnant. These results provided exciting clinical evidence that functional transplanted islets could be imaged in vivo with a tracer specific to GLP-1R. However, this method is associated with several disadvantages for the patients. Firstly, image quality of the grafts had a relative low resolution. In addition, in the clinical setting the grafts are usually transplanted into the liver.

Radiopharmaceuticals have to be cleared from the background to achieve acceptable target-to-background ratios, often requiring acquisition of late images, which might decrease image quality even further. Furthermore, injection of the probes must be repeated for long-term monitoring resulting in a relatively high radiation burden.

Ultrasound Imaging for Islet Transplantation

Recently, Sakata et al. [95] reported on a clinical case of a 39-y-old man, who had an episode of pancreatic bleeding due to chronic pancreatitis and who received total pancreatectomy with islet autotransplantation. Intraoperative ultrasound (US) examination was done to detect transplanted islets. Islet isolation from the resected total pancreas was performed and approximately 230,000 islet equivalents were acquired (Fig. 4). A double lumen

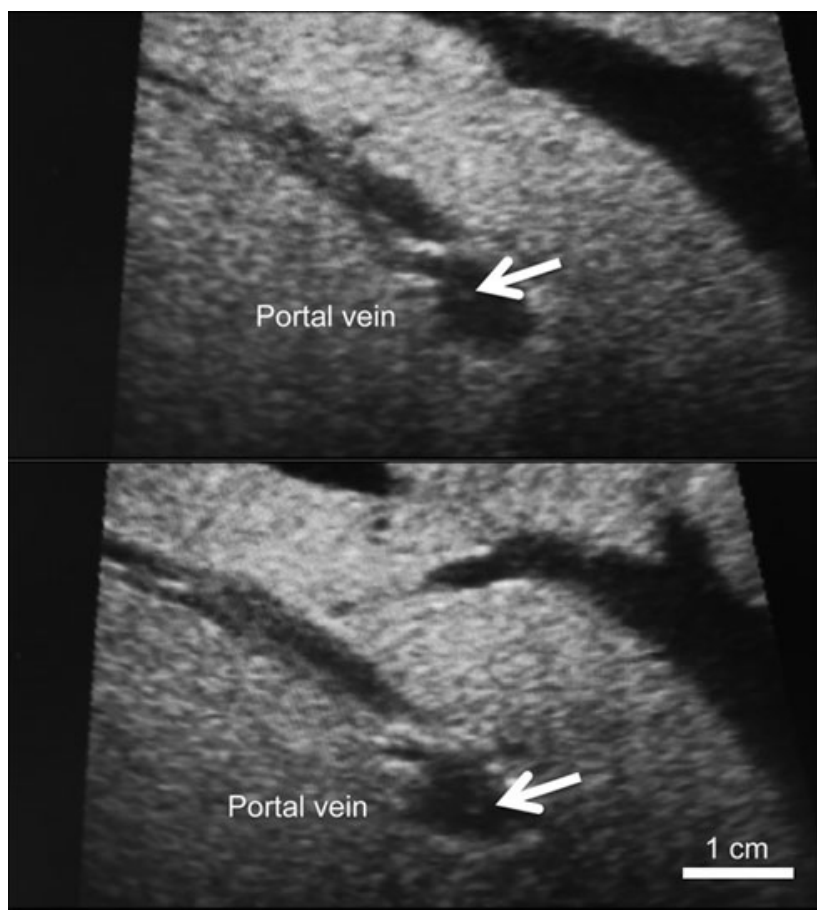

Fig. 4 Intraoperative ultrasound findings of the portal vein. The transplanted islets appeared as hyperechoic clusters in the portal vein (arrows). Reprinted from Islets. 2012, 4:339-342, Landes Bioscience publication, with permission 
catheter, used for transplantation and for monitoring the portal vein pressure, was inserted into the portal vein via the superior mesenteric vein, and the tip of the catheter was positioned at the bifurcation of the anterior and posterior branch of the portal vein to selectively infuse the islets into the right lobe of the liver. Intraoperative US examination revealed the transplanted islets as hyperechoic clusters that flowed from the tip of the catheter to the periphery of the portal vein. This was the first report of successful visualizing of human islets transplantation using US examination. Intraoperative US examination can be useful for detecting islets during transplantation in a clinical setting aiding to the evaluation of the safety of the procedure. This clinical modality could also be useful for evaluating and monitoring focal fatty infitration (steatosis) that could accompany islet transplantation $[6,96]$.

\section{Conclusions}

Although the studies described above provide an excellent proof of concepts for potential application of molecular imaging in diabetes, several issues have to be considered for clinical translation. Radioactive imaging agents, like diagnostic drugs generally, undergo a drug development process that parallels that of therapeutic agents, with similar development times but substantially smaller markets [97]. The commercial development of imaging agents for small patient populations is blocked by the limited revenues available with current per-dose pricing and the relatively small numbers of imaging procedures that would be performed [97]. In November 2008, production of Feridex ${ }^{\circledR}$ (ferumoxides) [98], which is a clinically approved contrast agent for the detection of liver lesions by MRI from AMAG Pharmaceuticals, was discontinued by the company. This contrast agent was one of the most widely tested probes for in vivo cell tracking using MRI. Therefore, a wide-ranging discussion on the best approaches to allow new diagnostic imaging agents to be developed as part of the health care system for patients' benefits is needed [97]. The translation of novel contrast agents from experimental studies to the clinical applications will require a significant amount of preparation by the investigators for successful evaluation of the agent in phase I clinical trials including discussions with the FDA and preparation of the investigative new drug (IND) submission [99].

All these factors have to be considered when designing and testing new molecular imaging agents for beta cell imaging. Although significant hurdles remain, recent advances indicate that BCM evaluation and monitoring of transplanted islet are becoming achievable goals. It is likely that with the development of molecular imaging methods and specific probes, clinicians will soon be able to obtain valuable information regarding the course of the disease and the success of therapy, which will offer new approaches for stratifying patients to anti-diabetic therapies [12, 100]. Although the enormous step toward this goal has been taken, significant work remains to be done before individualized medicine becomes a reality for diabetes patients.

Disclosure Ping Wang and Anna Moore declare that they have no conflict of interest.

Human and Animal Rights and Informed Consent This article does not contain any studies with human or animal subjects performed by any of the authors.

\section{References}

Papers of particular interest, published recently, have been highlighted as:

- Of importance,

-. Of major importance

1. Lin M, Lubag A, McGuire MJ, Seliounine SY, Tsyganov EN, Antich PP, et al. Advances in molecular imaging of pancreatic beta cells. Front Biosci. 2008;13:4558-75.

2. Shaw JE, Sicree RA, Zimmet PZ. Global estimates of the prevalence of diabetes for 2010 and 2030. Diabetes Res Clin Pract. 2010;87(1):4-14. doi:10.1016/j.diabres.2009.10.007.

3. Shah A, Mital D. Molecular imaging for diagnosis and management of diabetes-a review. Int $\mathbf{J}$ Medical Engineering and Informatics. 2012;4(4):325-42.

4. Callard F, Rose D, Wykes T. Close to the bench as well as at the bedside: involving service users in all phases of translational research. Health Expect. 2012;15(4):389-400. doi:10.1111/j. 1369-7625.2011.00681.x.

5. Marincola FM. Translational medicine: a two-way road. J Transl Med. 2003;1(1):1. doi:10.1186/1479-5876-1-1.

6. Di Gialleonardo V, de Vries EF, Di Girolamo M, Quintero AM, Dierckx RA, Signore A. Imaging of beta-cell mass and insulitis in insulin-dependent (Type 1) diabetes mellitus. Endocr Rev. 2012;33(6):892-919. doi:10.1210/er.2011-1041.

7. Zhang L, Eisenbarth GS. Prediction and prevention of Type 1 diabetes mellitus. J Diabetes. 2011;3(1):48-57. doi:10.1111/j. 1753-0407.2010.00102.x.

8. Weir GC, Marselli L, Marchetti P, Katsuta H, Jung MH, Bonner-Weir S. Towards better understanding of the contributions of overwork and glucotoxicity to the beta-cell inadequacy of type 2 diabetes. Diabetes Obes Metab. 2009;11(Suppl 4):82-90. doi:10.1111/j.1463-1326.2009.01113.x.

9. Kahn SE. Quantifying beta-cells in health and disease: the past, the present, and the need. Diabetes Care. 2013;36(1):4-5. doi: $10.2337 / \mathrm{dc} 12-1526$.

10. Saisho Y, Butler AE, Manesso E, Elashoff D, Rizza RA, Butler PC. Beta-cell mass and turnover in humans: effects of obesity and aging. Diabetes Care. 2013;36(1):111-7. doi:10.2337/dc120421.

11. Ritzel RA, Butler AE, Rizza RA, Veldhuis JD, Butler PC. Relationship between beta-cell mass and fasting blood glucose concentration in humans. Diabetes Care. 2006;29(3):717-8.

12. Goke B. What are the potential benefits of clinical beta-cell imaging in diabetes mellitus? Curr Pharm Des. 2010;16(14): 1547-9. 
13. Moore A. Advances in beta-cell imaging. Eur J Radiol. 2009;70(2):254-7. doi:10.1016/j.ejrad.2009.01.044.

14. Wang P, Medarova Z, Moore A. Molecular imaging: a promising tool to monitor islet transplantation. J Transplant. 2011;2011:202915. doi:10.1155/2011/202915.

15. Lebastchi J, Herold KC. Immunologic and metabolic biomarkers of beta-cell destruction in the diagnosis of type 1 diabetes. Cold Spring Harb Perspect Med. 2012;2(6):a007708. doi:10.1101/ cshperspect.a007708.

16. Gimi B, Leoni L, Oberholzer J, Braun M, Avila J, Wang Y, et al. Functional MR microimaging of pancreatic beta-cell activation. Cell Transplant. 2006;15(2):195-203.

17. Antkowiak PF, Tersey SA, Carter JD, Vandsburger MH, Nadler JL, Epstein FH, et al. Noninvasive assessment of pancreatic beta-cell function in vivo with manganese-enhanced magnetic resonance imaging. Am J Physiol Endocrinol Metab. 2009; 296(3):E573-8. doi:10.1152/ajpendo.90336.2008.

18. Leoni L, Roman BB. MR imaging of pancreatic islets: tracking isolation, transplantation and function. Curr Pharm Des. 2010; 16(14):1582-94.

19. Leoni L, Serai SD, Haque ME, Magin RL, Roman BB. Functional MRI characterization of isolated human islet activation. NMR Biomed. 2010;23(10):1158-65. doi:10.1002/nbm. 1542.

20. Leoni L, Dhyani A, La Riviere P, Vogt S, Lai B, Roman BB. Beta-cell subcellular localization of glucose-stimulated $\mathrm{Mn}$ uptake by X-ray fluorescence microscopy: implications for pancreatic MRI. Contrast Media Mol Imaging. 2011;6(6): 474-81. doi:10.1002/cmmi.447.

21. Lamprianou S, Immonen R, Nabuurs C, Gjinovci A, Vinet L, Montet $\mathrm{XC}$, et al. High-resolution magnetic resonance imaging quantitatively detects individual pancreatic islets. Diabetes. 2011;60(11):2853-60. doi:10.2337/db11-0726.

22. Antkowiak PF, Vandsburger MH, Epstein FH. Quantitative pancreatic beta cell MRI using manganese-enhanced LookLocker imaging and two-site water exchange analysis. Magn Reson Med. 2012;67(6):1730-9. doi:10.1002/mrm.23139.

23. Antkowiak PF, Stevens BK, Nunemaker CS, McDuffie M, Epstein FH. Manganese-enhanced magnetic resonance imaging detects declining pancreatic beta-cell mass in a cyclophosphamide-accelerated mouse model of type 1 diabetes. Diabetes. 2013;62(1):44-8. doi:10.2337/db12-0153.

24. • Botsikas D, Terraz S, Vinet L, Lamprianou S, Becker CD, Bosco D et al. Pancreatic magnetic resonance imaging after manganese injection distinguishes type 2 diabetic and normoglycemic patients. Islets. 2012;4(3):243-8. doi:10.4161/isl.20857. One of the earliest papers that describes application of manganese-enhanced magnetic resonance imaging in T2D patients.

25. Silva AC, Lee JH, Aoki I, Koretsky AP. Manganese-enhanced magnetic resonance imaging (MEMRI): methodological and practical considerations. NMR Biomed. 2004;17(8):532-43. doi: 10.1002/nbm.945.

26. - Lubag AJ, De Leon-Rodriguez LM, Burgess SC, Sherry AD. Noninvasive MRI of beta-cell function using a $\mathrm{Zn} 2+$-responsive contrast agent. Proc Natl Acad Sci U S A. 2011;108(45): 18400-5. doi:10.1073/pnas.1109649108. Demonstrated the feasibility of utilizing zinc-responsive T1 contrast MR imaging for monitoring islet beta-cells function in animal models.

27. De Leon-Rodriguez L, Lubag AJ Jr, Sherry AD. Imaging free zinc levels in vivo-what can be learned? Inorganica Chim Acta. 2012;393:12-23. doi:10.1016/j.ica.2012.06.026.

28. Malaisse WJ, Maedler K. Imaging of the beta-cells of the islets of Langerhans. Diabetes Res Clin Pract. 2012;98(1):11-8. doi: 10.1016/j.diabres.2012.07.001.

29. Esqueda AC, Lopez JA, Andreu-de-Riquer G, Alvarado-Monzon JC, Ratnakar J, Lubag AJ, et al. A new gadolinium-based
MRI zinc sensor. J Am Chem Soc. 2009;131(32):11387-91. doi: 10.1021/ja901875v.

30. Wangler B, Beck C, Shiue CY, Schneider S, Schwanstecher C, Schwanstecher M, et al. Synthesis and in vitro evaluation of (S)2-([11C]methoxy)-4-[3-methyl-1-(2-piperidine-1-yl-phenyl)-butylcarbamoyl]-be nzoic acid ([11C]methoxy-repaglinide): a potential beta-cell imaging agent. Bioorg Med Chem Lett. 2004;14(20): 5205-9. doi:10.1016/j.bmcl.2004.07.059.

31. Wangler B, Schneider S, Thews O, Schirrmacher E, Comagic S, Feilen P, et al. Synthesis and evaluation of (S)-2-(2-[18F]fluoroethoxy)-4-([3-methyl-1-(2-piperidin-1-yl-phenyl)-butyl-carbam oyl]-methyl)-benzoic acid ([18F]repaglinide): a promising radioligand for quantification of pancreatic beta-cell mass with positron emission tomography (PET). Nucl Med Biol. 2004; 31(5):639-47. doi:10.1016/j.nucmedbio.2004.01.007.

32. Schmitz A, Shiue CY, Feng Q, Shiue GG, Deng S, Pourdehnad MT, et al. Synthesis and evaluation of fluorine-18 labeled glyburide analogs as beta-cell imaging agents. Nucl Med Biol. 2004;31(4):483-91. doi:10.1016/j.nucmedbio.2003.12.003.

33. Schneider S, Ueberberg S, Korobeynikov A, Schechinger W, Schwanstecher C, Schwanstecher M, et al. Synthesis and evaluation of a glibenclamide glucose-conjugate: a potential new lead compound for substituted glibenclamide derivatives as islet imaging agents. Regul Pept. 2007;139(1-3):122-7. doi:10.1016/ j.regpep.2006.11.004.

34. Amartey JK, Esguerra C, Al-Jammaz I, Parhar RS, Al-Otaibi B. Synthesis and evaluation of radioiodinated substituted beta-naphthylalanine as a potential probe for pancreatic beta-cells imaging. Appl Radiat Isot. 2006;64(7):769-77. doi:10.1016/j.apradiso.2006. 01.009.

35. Amartey JK, Shi Y, Al-Jammaz I, Esguerra C, Al-Otaibi B, AlMohanna F. Radioiodinated naphthylalanine derivatives targeting pancreatic beta cells in normal and nonobese diabetic mice. Exp Diabetes Res. 2008;2008:371716. doi:10.1155/2008/371716.

36. Ericson LE, Hakanson R, Lundquist I. Accumulation of dopamine in mouse pancreatic B-cells following injection of L-DOPA. Localization to secretory granules and inhibition of insulin secretion. Diabetologia. 1977;13(2):117-24.

37. Koopmans KP, Neels OC, Kema IP, Elsinga PH, Sluiter WJ, Vanghillewe K, et al. Improved staging of patients with carcinoid and islet cell tumors with 18F-dihydroxy-phenyl-alanine and 11C-5-hydroxy-tryptophan positron emission tomography. J Clin Oncol. 2008;26(9):1489-95. doi:10.1200/JCO.2007.15.1126.

38. Mukai E, Toyoda K, Kimura H, Kawashima H, Fujimoto H, Ueda M, et al. GLP-1 receptor antagonist as a potential probe for pancreatic beta-cell imaging. Biochem Biophys Res Commun. 2009;389(3):523-6. doi:10.1016/j.bbrc.2009.09.014.

39. Reiner T, Kohler RH, Liew CW, Hill JA, Gaglia J, Kulkarni RN, et al. Near-infrared fluorescent probe for imaging of pancreatic beta cells. Bioconjug Chem. 2010;21(7):1362-8. doi:10.1021/bc100184w.

40. Reiner T, Thurber G, Gaglia J, Vinegoni C, Liew CW, Upadhyay R, et al. Accurate measurement of pancreatic islet beta-cell mass using a second-generation fluorescent exendin-4 analog. Proc Natl Acad Sci U S A. 2011;108(31):12815-20. doi: 10.1073/pnas.1109859108.

41. Wang Y, Lim K, Normandin M, Zhao X, Cline GW, Ding YS. Synthesis and evaluation of [18F]exendin (9-39) as a potential biomarker to measure pancreatic beta-cell mass. Nucl Med Biol. 2012;39(2):167-76. doi:10.1016/j.nucmedbio.2011.07.011.

42. Moore A, Bonner-Weir S, Weissleder R. Noninvasive in vivo measurement of beta-cell mass in mouse model of diabetes. Diabetes. 2001;50(10):2231-6.

43. Garcia A, Mirbolooki MR, Constantinescu C, Pan ML, Sevrioukov E, Milne N, et al. 18F-Fallypride PET of pancreatic islets: in vitro and in vivo rodent studies. $\mathrm{J}$ Nucl Med. 2011;52(7):1125-32. doi:10.2967/jnumed.111.088583. 
44. Simpson NR, Souza F, Witkowski P, Maffei A, Raffo A, Herron A, et al. Visualizing pancreatic beta-cell mass with [11C]DTBZ. Nucl Med Biol. 2006;33(7):855-64. doi:10.1016/j.nucmedbio. 2006.07.002.

45. Souza F, Simpson N, Raffo A, Saxena C, Maffei A, Hardy M, et al. Longitudinal noninvasive PET-based beta cell mass estimates in a spontaneous diabetes rat model. J Clin Invest. 2006;116(6):1506-13. doi:10.1172/JCI27645.

46. Kung MP, Hou C, Lieberman BP, Oya S, Ponde DE, Blankemeyer $\mathrm{E}$, et al. In vivo imaging of beta-cell mass in rats using 18F-FP-(+)-DTBZ: a potential PET ligand for studying diabetes mellitus. J Nucl Med. 2008;49(7):1171-6. doi:10.2967/jnumed. 108.051680 .

47. Tsao HH, Lin KJ, Juang JH, Skovronsky DM, Yen TC, Wey SP, et al. Binding characteristics of 9-fluoropropyl-(+)-dihydrotetrabenzazine $(\mathrm{AV}-133)$ to the vesicular monoamine transporter type 2 in rats. Nucl Med Biol. 2010;37(4):413-9. doi:10.1016/ j.nucmedbio.2010.01.002.

48. Virostko J, Henske J, Vinet L, Lamprianou S, Dai C, Radhika A, et al. Multimodal image coregistration and inducible selective cell ablation to evaluate imaging ligands. Proc Natl Acad Sci U S A. 2011;108(51):20719-24. doi:10.1073/pnas.1109480108.

49. Singhal T, Ding YS, Weinzimmer D, Normandin MD, Labaree $\mathrm{D}$, Ropchan J, et al. Pancreatic beta cell mass PET imaging and quantification with [11C]DTBZ and [18F]FP-(+)-DTBZ in rodent models of diabetes. Mol Imaging Biol. 2011;13(5): 973-84. doi:10.1007/s11307-010-0406-x.

50. - Clark PB, Gage HD, Brown-Proctor C, Buchheimer N, CallesEscandon J, Mach RH et al. Neurofunctional imaging of the pancreas utilizing the cholinergic PET radioligand [18F]4-fluorobenzyltrozamicol. Eur J Nucl Med Mol Imaging. 2004;31(2): 258-60. doi:10.1007/s00259-003-1350-7. Novel study that demonstrated the feasibility of $18 F-F B T$ PET presynaptic vesicular acetylcholine transporter imaging for detection of $B C M$ in non-human primates and human subjects.

51. Pettibone DJ, Totaro JA, Pflueger AB. Tetrabenazine-induced depletion of brain monoamines: characterization and interaction with selected antidepressants. Eur J Pharmacol. 1984;102(3-4): 425-30.

52. Ichise M, Harris PE. Imaging of beta-cell mass and function. J Nucl Med. 2010;51(7):1001-4. doi:10.2967/jnumed.109.068999.

53. - Freeby M, Goland R, Ichise M, Maffei A, Leibel R, Harris P. VMAT2 quantitation by PET as a biomarker for beta-cell mass in health and disease. Diabetes Obes Metab. 2008;10 Suppl 4:98-108. doi:10.1111/j.1463-1326.2008.00943.x. The first study that showed the feasibility of 11C-DTBZ PET imaging of the pancreas in long-standing TID patients and healthy control subjects.

54. Goland R, Freeby M, Parsey R, Saisho Y, Kumar D, Simpson N, et al. 11C-dihydrotetrabenazine PET of the pancreas in subjects with long-standing type 1 diabetes and in healthy controls. J Nucl Med. 2009;50(3):382-9. doi:10.2967/jnumed.108.054866.

55. Eriksson O, Jahan M, Johnstrom P, Korsgren O, Sundin A, Halldin C, et al. In vivo and in vitro characterization of [18F]FE-(+)-DTBZ as a tracer for beta-cell mass. Nucl Med Biol. 2010;37(3):357-63. doi:10.1016/j.nucmedbio.2009.12.004.

56. • Lin KJ, Weng YH, Wey SP, Hsiao IT, Lu CS, Skovronsky D et al. Whole-body biodistribution and radiation dosimetry of 18F-FP-(+)-DTBZ (18F-AV-133): a novel vesicular monoamine transporter 2 imaging agent. J Nucl Med. 2010;51(9): 1480-5. doi:10.2967/jnumed.110.078196. Novel study that investigated biodistribution and radiation dosimetry of $18 \mathrm{~F}-\mathrm{AV}$ 133 in humans.

57. - Jahan M, Eriksson O, Johnstrom P, Korsgren O, Sundin A, Johansson L et al. Decreased defluorination using the novel beta-cell imaging agent [18F]FE-DTBZ-d4 in pigs examined by
PET. EJNMMI Res. 2011;1(1):33. doi:10.1186/2191-219X-1-33. Tested in vivo pharmacokinetics and pharmacodynamics of $18 \mathrm{~F}$ FE-DTBZ-d4 in a large animal model by PET/CT imaging.

58. - Normandin MD, Petersen KF, Ding YS, Lin SF, Naik S, Fowles $\mathrm{K}$ et al. In vivo imaging of endogenous pancreatic betacell mass in healthy and type 1 diabetic subjects using $18 \mathrm{~F}$ fluoropropyl-dihydrotetrabenazine and PET. J Nucl Med. 2012;53(6):908-16. doi:10.2967/jnumed.111.100545. One of the earliest studies that evaluated $18 F-A V-133$ for quantitative PET imaging of BCM in healthy control subjects and T1D patients.

59. Kwee TC, Basu S, Saboury B, Torigian DA, Naji A, Alavi A. Beta-cell imaging: opportunities and limitations. J Nucl Med. 2011;52(3):493; author reply -5. doi:10.2967/jnumed.110.085530.

60. Blomberg BA, Moghbel MC, Alavi A. PET imaging of beta-cell mass: is it feasible? Diabetes Metab Res Rev. 2012;28(7):601-2. doi:10.1002/dmrr.2314.

61. Blomberg BA, Codreanu I, Cheng G, Werner TJ, Alavi A. Beta-cell imaging: call for evidence-based and scientific approach. Mol Imaging Biol. 2013;15(2):123-30. doi:10.1007/s11307-013-0620-4.

62. Blomberg BA, Eriksson O, Saboury B, Alavi A. Beta-cell mass imaging with DTBZ positron emission tomography: is it possible? Mol Imaging Biol. 2013;15(1):1-2. doi:10.1007/s11307012-0593-8

63. McCall M, Shapiro AM. Update on islet transplantation. Cold Spring Harb Perspect Med. 2012;2(7):a007823. doi:10.1101/ cshperspect.a007823.

64. Rother KI, Harlan DM. Challenges facing islet transplantation for the treatment of type 1 diabetes mellitus. J Clin Invest. 2004;114(7):877-83. doi:10.1172/JCI23235.

65. Ryan EA, Paty BW, Senior PA, Bigam D, Alfadhli E, Kneteman NM, et al. Five-year follow-up after clinical islet transplantation. Diabetes. 2005;54(7):2060-9.

66. Medarova Z, Moore A. Non-invasive detection of transplanted pancreatic islets. Diabetes Obes Metab. 2008;10(Suppl 4): 88-97. doi:10.1111/j.1463-1326.2008.00942.x.

67. Jirak D, Kriz J, Herynek V, Andersson B, Girman P, Burian M, et al. MRI of transplanted pancreatic islets. Magn Reson Med. 2004;52(6):1228-33. doi:10.1002/mrm.20282.

68. Evgenov NV, Medarova Z, Dai G, Bonner-Weir S, Moore A. In vivo imaging of islet transplantation. Nat Med. 2006;12(1): 144-8. doi:10.1038/nm1316.

69. Evgenov NV, Medarova Z, Pratt J, Pantazopoulos P, Leyting S, Bonner-Weir $S$, et al. In vivo imaging of immune rejection in transplanted pancreatic islets. Diabetes. 2006;55(9):2419-28. doi:10.2337/db06-0484.

70. Tai JH, Foster P, Rosales A, Feng B, Hasilo C, Martinez V, et al. Imaging islets labeled with magnetic nanoparticles at 1.5 Tesla. Diabetes. 2006;55(11):2931-8. doi:10.2337/db06-0393.

71. Biancone L, Crich SG, Cantaluppi V, Romanazzi GM, Russo S, Scalabrino E, et al. Magnetic resonance imaging of gadoliniumlabeled pancreatic islets for experimental transplantation. NMR Biomed. 2007;20(1):40-8. doi:10.1002/nbm.1088.

72. Barnett BP, Ruiz-Cabello J, Hota P, Ouwerkerk R, Shamblott $\mathrm{MJ}$, Lauzon $\mathrm{C}$, et al. Use of perfluorocarbon nanoparticles for non-invasive multimodal cell tracking of human pancreatic islets. Contrast Media Mol Imaging. 2011;6(4):251-9. doi: 10.1002/cmmi.424.

73. Barnett BP, Ruiz-Cabello J, Hota P, Liddell R, Walczak P, Howland V, et al. Fluorocapsules for improved function, immunoprotection, and visualization of cellular therapeutics with MR, US, and CT imaging. Radiology. 2011;258(1):182-91. doi: 10.1148/radiol.10092339.

74. - Barnett BP, Arepally A, Karmarkar PV, Qian D, Gilson WD, Walczak P et al. Magnetic resonance-guided, real-time targeted delivery and imaging of magnetocapsules immunoprotecting pancreatic islet cells. Nat Med. 2007;13(8):986-91. doi: 
10.1038/nm1581. The first work to demonstrate the feasibility of MRI detection of human islets labeled with immunoprotective iron oxide-loaded magnetic capsules in large animals.

75. - Medarova Z, Vallabhajosyula P, Tena A, Evgenov N, Pantazopoulos $\mathrm{P}$, Tchipashvili $\mathrm{V}$ et al. In vivo imaging of autologous islet grafts in the liver and under the kidney capsule in nonhuman primates. Transplantation. 2009;87(11):1659-66. doi: 10.1097/TP.0b013e3181a5cbc0. Established a method for the noninvasive, longitudinal detection of pancreatic islets transplanted into non-human primates using a low-field clinical MRI system.

76. Toso C, Vallee JP, Morel P, Ris F, Demuylder-Mischler S, Lepetit-Coiffe $\mathrm{M}$, et al. Clinical magnetic resonance imaging of pancreatic islet grafts after iron nanoparticle labeling. Am J Transplant. 2008;8(3):701-6. doi:10.1111/j.1600-6143.2007. 02120.x.

77. • Saudek F, Jirak D, Girman P, Herynek V, Dezortova M, Kriz J et al. Magnetic resonance imaging of pancreatic islets transplanted into the liver in humans. Transplantation. 2010;90(12): 1602-6. Showed that MR imaging of iron nanoparticle labeled islets became a technique readily available in the clinic for evaluation of initial islet engraftment and survival.

78. Christoffersson G, Henriksnas J, Johansson L, Rolny C, Ahlstrom H, Caballero-Corbalan J, et al. Clinical and experimental pancreatic islet transplantation to striated muscle: establishment of a vascular system similar to that in native islets. Diabetes. 2010;59(10):2569-78. doi:10.2337/db10-0205.

79. Christoffersson G, Carlsson PO, Phillipson M. Intramuscular islet transplantation promotes restored islet vascularity. Islets. 2011;3(2):69-71.

80. Echeverri GJ, McGrath K, Bottino R, Hara H, Dons EM, van der Windt DJ, et al. Endoscopic gastric submucosal transplantation of islets (ENDO-STI): technique and initial results in diabetic pigs. Am J Transplant. 2009;9(11):2485-96. doi:10.1111/j. 1600-6143.2009.02815.x.

81. Fujita M, McGrath KM, Bottino R, Dons EM, Long C, Kumar $\mathrm{G}$, et al. Technique of endoscopic biopsy of islet allografts transplanted into the gastric submucosal space in pigs. Cell Transplant. 2013. doi:10.3727/096368912X662381.

82. Schubert U, Schmid J, Lehmann S, Zhang XY, Morawietz H, Block NL, et al. Transplantation of pancreatic islets to adrenal gland is promoted by agonists of growth-hormone-releasing hormone. Proc Natl Acad Sci U S A. 2013;110(6):2288-93. doi: 10.1073/pnas. 1221505110 .

83. Toso C, Zaidi H, Morel P, Armanet M, Andres A, Pernin N, et al. Positron-emission tomography imaging of early events after transplantation of islets of Langerhans. Transplantation. 2005;79(3):353-5.

84. - Eich T, Eriksson O, Sundin A, Estrada S, Brandhorst D, Brandhorst $\mathrm{H}$ et al. Positron emission tomography: a real-time tool to quantify early islet engraftment in a preclinical large animal model. Transplantation. 2007;84(7):893-8. doi:10.1097/ 01.tp.0000284730.86567.9f. Demonstrated the feasibility of $18 F-F D G$ PET imaging on transplanted islets in a preclinical large animal model.

85. •- Eriksson O, Eich T, Sundin A, Tibell A, Tufveson G, Andersson $\mathrm{H}$ et al. Positron emission tomography in clinical islet transplantation. Am J Transplant. 2009;9(12):2816-24. doi:10.1111/j.1600-6143.2009.02844.x. First clinical study that describes 18F-FDG PET imaging of islets transplanted into T1D patients.

86. Zhang Y, Chen W. Radiolabeled glucagon-like peptide-1 analogues: a new pancreatic beta-cell imaging agent. Nucl Med Commun. 2012;33(3):223-7. doi:10.1097/MNM.0b013e32834e7f47.

87. Brom M, Oyen WJ, Joosten L, Gotthardt M, Boerman OC. 68 Ga-labelled exendin-3, a new agent for the detection of insulinomas with PET. Eur J Nucl Med Mol Imaging. 2010; 37(7):1345-55. doi:10.1007/s00259-009-1363-y.

88. Kiesewetter DO, Gao H, Ma Y, Niu G, Quan Q, Guo N, et al. 18F-radiolabeled analogs of exendin-4 for PET imaging of GLP1 in insulinoma. Eur J Nucl Med Mol Imaging. 2012;39(3): 463-73. doi:10.1007/s00259-011-1980-0.

89. Boerman OC, Gotthardt M. 18F-Labelled exendin to image GLP-1 receptor-expressing tissues: from niche to blockbuster? Eur J Nucl Med Mol Imaging. 2012;39(3):461-2. doi:10.1007/ s00259-011-2020-9.

90. Kiesewetter DO, Guo N, Guo J, Gao H, Zhu L, Ma Y, et al. Evaluation of an [(18)F]AlF-NOTA analog of exendin-4 for imaging of GLP-1 receptor in insulinoma. Theranostics. 2012; 2(10):999-1009. doi:10.7150/thno.5276.

91. Wu Z, Todorov I, Li L, Bading JR, Li Z, Nair I, et al. In vivo imaging of transplanted islets with 64Cu-DO3A-VS-Cys40Exendin-4 by targeting GLP-1 receptor. Bioconjug Chem. 2011; 22(8):1587-94. doi:10.1021/bc200132t.

92. Wu Z, Liu S, Hassink M, Nair I, Park R, Li L, et al. Development and evaluation of 18F-TTCO-Cys40-Exendin-4: a PET probe for imaging transplanted islets. J Nucl Med. 2013;54(2): 244-51. doi:10.2967/jnumed.112.109694.

93. Christ E, Wild D, Forrer F, Brandle M, Sahli R, Clerici T, et al. Glucagon-like peptide-1 receptor imaging for localization of insulinomas. J Clin Endocrinol Metab. 2009;94(11):4398-405. doi:10.1210/jc.2009-1082.

94. •• Pattou F, Kerr-Conte J, Wild D. GLP-1-receptor scanning for imaging of human beta cells transplanted in muscle. $\mathrm{N}$ Engl $\mathrm{J}$ Med. 2010;363(13):1289-90. doi:10.1056/NEJMc1004547. The first clinical case report of ${ }^{111}$ In-DOTA-exendin-4 SPECT imaging for visualizing transplanted islets in the left forearm of one patient.

95. Sakata N, Goto M, Gumpei Y, Mizuma M, Motoi F, Satomi S, et al. Intraoperative ultrasound examination is useful for monitoring transplanted islets: a case report. Islets. 2012;4(5): 339-42. doi:10.4161/isl.22384.

96. Low G, Hussein N, Owen RJ, Toso C, Patel VH, Bhargava R, et al. Role of imaging in clinical islet transplantation. Radiographics. 2010;30(2):353-66. doi:10.1148/rg.302095741.

97. Josephson L, Rudin M. Barriers to clinical translation with diagnostic drugs. J Nucl Med. 2013;54(3):329-32. doi:10.2967/ jnumed.112.107615.

98. Wang YX. Superparamagnetic iron oxide based MRI contrast agents: current status of clinical application. Quant Imaging Med Surg. 2011;1(1):35-40. doi:10.3978/j.issn.2223-4292.2011. 08.03 .

99. Arbab AS, Janic B, Haller J, Pawelczyk E, Liu W, Frank JA. In vivo cellular imaging for translational medical research. Curr Med Imaging Rev. 2009;5(1):19-38. doi:10.2174/15734050978 7354697.

100. Medarova Z, Moore A. MRI in diabetes: first results. AJR Am J Roentgenol. 2009;193(2):295-303. doi:10.2214/AJR.08.2156. 